\title{
Nuevos usuarios, nuevos documentos
}

\author{
Carmen Agustín Lacruz \\ Departamento de Ciencias de la Documentación \\ e Historia de la Ciencia \\ Universidad de Zaragoza \\ Mercedes Muñoz Escolá \\ Documentalista
}

\subsection{Resumen}

Se analizan las modificaciones que tienen lugar en el proceso comunicativo documental cuando, fruto de las innovaciones tecnológicas, el documento analógico da paso al documento digital. Se abordan las nuevas formas de organización y transmisión de la información y la forma en que afectan al usuario (Autor)

Palabras clave: Documentos analógicos. Documentos digitales. Usuarios. Proceso comunicativo digital. Hipertexto. Hipermedia.

\subsection{Abstract}

Analysis of how the transition from analogic documents to digital ones modifies the documentary communication proccess. The new forms of organizing and transmitting information are considered, especially in relation to their incidence on users.

Keywords: Analogic documents. Digital documents. Users. Digital communication proccess. Hypertext. Hipermedia.

\section{Introducción}

Este trabajo forma parte de un proyecto común y más amplio que dedicamos a los usuarios y su posición dentro de los sistemas de información y como elemento fundamental del proceso comunicativo documental.

Los usuarios nos interesan como objeto de trabajo porque pensamos que constituyen uno de los elementos más desatendidos en la contemplación de los nuevos sistemas que surgen fruto de la presencia de los documentos digitales.

Por ello es preciso incidir en que cuando nos encontramos con un proceso comunicativo documental en el que está presente un documento digital, algo 
más que el soporte cambia; cambia el canal, el código y también la organización de la información. Por tanto la naturaleza del mensaje se modifica.

Si estos elementos varían el sujeto inicial o final, según la perspectiva desde la que se contemple el proceso, es decir, el usuario o receptor del mensaje no permanece ni impasible ni invariable.

Aunque el soporte sea electrónico y la forma de representación de la información sea digital, el usuario sigue estando constituido por átomos y necesidades de información. Lo que es relevante para nosotros, en tanto que profesionales de la Documentación, es que los usuarios tienen necesidades de información que vamos a cubrir mediante documentos electrónicos. Estos documentos suponen mucho más que un nuevo soporte:

1. Generan una nueva manera de organizar y transmitir la información e

2. Implican un tipo de interrelación diferente con el usuario.

\section{El documento, un proceso evolutivo constante}

La sensación de desconcierto, incertidumbre y desazón que experimentamos en la actualidad cuando nos enfrentamos a los nuevos documentos electrónicos es similar a la experimentada a lo largo de la historia, ante situaciones de cambio en los modelos científico-técnicos.

El documento digital, no es tanto una realidad complementamente revolucionaria y rupturista respecto de productos anteriores, como el fruto de una evolución previa que se ha desarrollado de forma constante a lo largo del tiempo. Esta evolución ha sido jalonada por algunos hitos importante, entre los cuales merece la pena destacar:

- El momento en el que, a finales del IV milenio a. C., entre los sumerios aparece la primera constatación documental de una actividad humana. Es decir, el momento en el que comienza a difundirse un sistema de escritura conocido como cuneiforme, que permite contabilizar las posesiones del templo y dar cuenta de sus transacciones económicas.

- La aparición del alifato en las costas fenicias al final de la primera mitad del segundo milenio supuso el nacimiento de un código que se caracterizaba por la utilización de un número limitado y pequeño de signos, que combinados entre sí permitían representar todos los sonidos de una lengua. El alfabeto aportó la economía de signos lo que facilitaba la difusión y uso del código.

- El tránsito desde el soporte papiro y el formato rollo hacia el soporte pergamino y el formato códice, tuvo lugar entre los siglos I y IV d. C. y facilitó el uso y el acceso al documento. 
- El paso, mediado el siglo XV, de la inscripción manual de los signos escriptorios sobre soporte pergamino a la inscripción mecánica sobre soporte papel, supuso la secularización y expansión de la cultura.

Por lo que respecta al momento presente, nos situamos en un nuevo estadio de transición dentro de este gran proceso evolutivo desarrollado a lo largo de seis milenios: A lo largo de los últimos 500 años que han conformado la era Gutemberg, el vehículo generalizado de transmisión de experiencias y conocimientos entre las generaciones y los pueblos ha sido el libro. Éste, salvo en los modos de producción, apenas ha sufrido pequeñas modificaciones en cuanto a sus aspectos formales, de organización y disposición del contenido.

A la vez los cambios tecnológicos que se han desarrollado en las últimas décadas han dado lugar a lo que se ha llamado "sociedad de la información", "era digital" o "era de la cibercultura". Como ha ocurrido siempre a lo largo de la historia, las nuevas tecnologías no sólo influyen en los medios de producción sino también en las estructuras básicas, tanto sociales como económicas. Las nuevas tecnologías, cualquiera que sea el tiempo en que se originen, cambian de forma sustancial nuestra manera de vivir la realidad. Las personas, normalmente, nos adentramos en el uso de las nuevas tecnologías, de forma intuitiva. En general el aprendizaje que actualmente realiza cualquier usuario de información es un aprendizaje autodidacta, incluso en los más jovenes, ya que la escuela está todavía lejos de incorporar nuevos métodos de aprendizaje basados en estas nuevas técnologías que el desarrollo científico-técnico ha propiciado.

El libro, en estos momentos, en los umbrales del año 2000, coexiste compitiendo con un nuevo soporte y una nueva forma de transmisión de la información, que ha surgido fruto del desarrollo de las nuevas tecnologías de la información: estamos hablando del soporte electromagnético y del denominado documento electrónico.

\section{Algunas precisiones terminológico-conceptuales}

La terminología utilizada en este nuevo contexto electrónico está desempeñando un importante papel como puente que vincula viejos y nuevos soportes, formatos y modos de representación. Hace posible que el sujeto utilice los términos tradicionales — libro, lectura, texto, página...-para significar los nuevos contenidos, facilitando de esta forma la evolución de modelos anteriores.

A esta altura de nuestra exposición, es necesario realizar algunas precisiones a proposito del concepto de documento electrónico.

A este respecto, Lluis Codina (1996, p. 27 y ss.) señala que se utilizan como sinonimos los términos electrónico y digital, cuando en realidad comportan significados distintos: no todo documento electrónico es un documento digital aun-

Scire. 3 : 1 (ene. -jun. 1997) 87-97 
que cualquier documento digital es un documento electrónico — por ejemplo una cinta de vídeo es un documento electrónico, pero no es un documento digital—. Tal como está teniendo lugar la evolución de los medios de comunicación y de la transmisión de la información la oposición más significativa ha dejado de ser la que existe entre los documentos electrónicos y los no electrónicos sino la que se da entre documentos analógicos y documentos digitales.

Un documento analógico representa la realidad por analogía física. Puede necesitar distintos aparatos que operen como mediadores en la descodificación de la señal (magnetoscopio, aparato de TV). Se caracterizan porque presentan una interactividad limitada, y porque su circulación requiere un desplazamiento físico del objeto (cinta de cassette, vídeo, libro, etc).

Frente a él el documento digital representa la realidad mediante códigos binarios (códigos digitales). Siempre necesita la intervención de un aparato de lectura (el ordenador). Se caracteriza porque, teoricamente, su interactividad es ilimitada, y en este caso, su circulación no implica un desplazamiento físico de los objetos sino de la energía en forma de bits.

Un nuevo grado de distinción dentro de los documentos digitales proviene del concepto de hipertextualidad. El hipertexto es, en estos momentos, un modelo teórico, una abstracción, una clase de programas informáticos y una clase o tipo de documento digital. De ahí la dificultad para definirlo y las confusiones generadas en torno a su conceptualización.

Como modelo teórico, el hipertexto constituye una propuesta para organizar la información de tal manera que sea posible leerla siguiendo las relaciones asociativas y no simplemente siguiendo la secuencialidad que impone la letra impresa en papel.

Como abstración, el hipertexto hace referencia a la aspiración utopica que animaba a Theodor Nelson, artífice del término, de introducir, organizar y recuperar toda la información del mundo en un sistema informático regido por el principio de asociación de ideas y documentos. Propósito, por otra parte, que se había erigido, a príncipios de siglo, en el eje rector del quehacer profesional de Paul Otlet.

El término tambien hace referencia a una clase de programas de ordenador que sirven para organizar y acceder a los documentos digitales por medio de relaciones asociativas

Finalmente, por extensión reciben la denominación de documentos hipertextuales o hipertextos aquellos elaborados y organizados deacuerdo con estos presupuestos. 


\section{Las modificaciones de los elementos en el proceso comunicati- vo-digital}

Todo proceso comunicativo se caracteriza por la presencia de un conjunto de elementos que se relacionan entre si: emisor, receptor, canal, mensaje código, de forma que si uno de estos elementos cambia, el resto de los elementos resulta modificado.

En un contexto informativo documental que trabaja con documentos digitales, el mensaje, el documento hipertextual / hipermedia, implica una nueva forma de codificar, organizar y transmitir la información que da lugar a transformaciones en el canal y el código. De esta manera resultan modificados el resto de los elementos que intervienen en dicho proceso: el emisor o productor del documento hipertextual y el receptor o usuario-lector.

La modificación que sufren emisor-productor y receptor-usuario es consustancial a la esencia misma del documento hipertextual. En él nada o casi nada es parecido al documento tradicional que está habituado a producir o leer. El emisor-productor tiene ante sí el reto de elaborar documentos en los que las informaciones contenidas se muestren ante el usuario de forma interactiva, organizándolas de manera que se aproximimen más a como su mente trabaja y piensa que a como sus ojos leen. Es decir la organización del conocimiento se hace de forma no necesariamente secuencial sino que sigue la estructura del pensamiento, esto es, por asociaciones. Si el emisor consigue una adecuada organización del hiperdocumento y logra dotarlo de unas buenas herramientas de uso, el receptor, aún dentro de sus primeras reticencias, puede encontrar en él un medio eficaz para encontrar información y conocimiento.

A su vez, también el usuario debe modificar sus hábitos de acceso. En un hiperdocumento o documento digital puede encontrar tres, cuatro o más tipos de códigos comunicativos diferentes: textual, imagen fija o móvil, sonido, símbolos etc. Esto le lleva a replantearse el acto lector. Su lectura ya no se centra unicamente en el texto escrito apoyado, en algunos casos, de la imagen fija; ahora el usuario va a encontrar una combinación de códigos entremezclados, lo que da lugar a una polilectura y supone por tanto un esfuerzo adicional al que se tendrá que ir acostumbrando.

Que duda cabe que toda novedad requiere un aprendizaje, y la lectura de hiperdocumentos, entendida el sentido más amplio que la palabra pueda tener como interpretación de significados, no es algo que se escape al aprendizaje. Creemos que éste puede ser corto en el tiempo siempre y cuando el productor ponga especial atención tanto en los intereses del futuro lector de su documento como en la organización de la información en él mismo.

Scire. 3 : 1 (ene. -jun. 1997) 87-97 


\section{Nuevos documentos, nuevos problemas}

El usuario ha ido, poco a poco, adaptándose a las nuevas técnologías de la información, pero ante el documento digital, en cualquiera de sus manifestaciones como hipertexto o hipermedia, muestra en general una actitud temerosa y recelosa. Este miedo viene generado porque lo que tiene ante sí no es un objeto físico con límites conocidos al que pueda acceder directamente sino que se enfrenta a algo cuya forma, volumen y extensión desconoce y al que además debe acceder mediatizado por una máquina, el ordenador.

Por otro lado el usuario percibe el documento hipertextual o hipermedia como una entidad global, cuyos límites reales desconoce puesto que los enlaces sobre los que se sustenta pueden llegar a ser muy numerosos y en el caso de las Webs ilimitados. Esta característica, básica por otra parte, del documento hipertextual puede llevar al usuario a sentir lo que diversos autores han convenido en llamar "desbordamiento cognitivo", y éste no es otra cosa que la incapacidad del usuario de procesar toda la información que le ofrece el documento hipertextual. Ante esta incapacidad se produce la angustia informativa, querer información, tenerla al alcance pero sentirnos incapaces de aprehenderla por rebasar nuestra capacidad intelectual y nuestro tiempo real. Nos encontramos ante el mismo problema que se señalaba años atrás respecto al crecimiento exponencial de la documentación sobre soporte papel, la sobreinformación o más bien la abundancia de información que nos lleva a optar por el rechazo a la misma y tiene como consecuencia la desinformación.

Otro problema que con cierta frecuencia sufre el usuario-lector de hiperdocumentos es la "desorientación". Tiene su origen en una doble causa; por una parte en el desconocimiento de los límites físicos reales del documento digital y por otra en la organización asociativa propia de los hiperdocumentos, hecho que rompe la secuencialidad. Esta desorientación puede provocar en el usuario la pérdida de su interés informativo.

Las soluciones para ambos problemas pueden ser variadas y en absoluto excluyentes y deben contemplarse desde una perspectiva global e integradora.

Ante todo es preciso delimitar adecuadamente el objeto del que trata el documento. Si al crear un documento hipertexto / hipermedia olvidamos el contenido fundamental y nos centramos unicamente en realizar los máximos enlaces posibles se corre el riesgo de presentar tanta y tan variada información que el usuario se sienta saturado y perdido ante semejante masa informativa.

Un productor de hiperdocumentos debe asumir que nunca colmará todas las asociaciones que la mente de los distintos usuarios puede llegar a generar. Ante esta realidad debe intentar en todo momento la creación de enlaces que incidan directamente en el tema tratado, de lo contrario podemos encontrarnos con enla-

Scire. 3 : 1 (ene. -jun. 1997) 87-97 
ces que en lugar de orientar el pensamiento del lector por medio de asociaciones posibles y pertinentes con el objeto, lo desorienten y creen confusión. Por ejemplo, ante el cuadro de Goya Casa de locos se puede crear un enlace orientativo con cuadros de otros autores que hayan tratado el tema de la locura, por el contrario un enlace desorientativo consistiría en relacionarlo con una bibliografía sobre la pintura como terapia de determinadas patologías psíquicas.

En el momento del diseño, el productor debe tener presente a su usuario final. Por ejemplo un documento hipertextual de orientación didáctica y dirigido a niños no puede incluir iconos que sólo la capacidad asociativa de un adulto pueda hacer reconocibles.

Para reducir la incidencia del sindrome de "desbordamiento cognitivo" el usuario debería establecer de antemano cuáles son los objetivos, intereses y niveles de extensión y profundidad que desea. De lo contrario, debido a las características del hiperdocumento, tenderá irremisiblemente a la dispersión y a la difusión o pérdida de sus objetivos.

Pero no siempre el usuario se acerca a un documento de este tipo con las ideas suficientemente claras. Éste es el motivo por el que se deben contemplar diferentes niveles de profundización en el acceso al hiperdocumento, lo que conlleva que el autor diseñe el contenido de manera que el usuario pueda elegir el nivel de profundización que se adecue a sus intereses y objetivos.

Para ello es necesario que el autor del mismo lo organice de forma lógica y racional atendiendo a un plan preestablecido que responda a una clara organización del conocimiento. Este aspecto es especialmente interesante, sobre todo si consideramos que en el diseño de documentos digitales todavía no ha dado tiempo a que se establezcan convenciones asumidas por usuarios y productores que permitan a unos y otros predeterminar cuales son las posiciones y emplazamientos convenidamente significativos.

La lectura del hiperdocumento se facilita si, en la medida de lo posible, el usuario tienen la posibilidad de conocer de antemano los límites del documento al que accede. Es decir, ya que no va a poder tomarlo entre sus manos, hojearlo, recorrerlo hasta el final y volver a cualquiera de sus partes, en suma hacerse con el objeto físico y su contenido intelectual, se le debe brindar la oportunidad de contemplarlo en su totalidad por medio de índices y mapas o sumarios. En cierta forma conocer los limites aproximados del objeto en el que se adentra aminora la angustia creada por el desbordamiento informativo.

Los mapas o sumarios estructuran la información y proporcionan una visión de conjunto del hiperdocumento. Pueden ser conceptuales, jerárquicos o una mezcla de ambos. 
Los índices representan por medio de palabras o frases los conceptos relevantes que aparecen en el documento y nos remiten a la parte o partes en las que se localizan dichos conceptos.

Otra de las ayudas que debe encontrar el usuario para no perderse por el documento son las distintas herramientas de orientación. Una vez que se ha adentrado en el documento va a necesitar señaladores que le proporcionen información contextual, es decir, que le indiquen en que punto del documento se encuentra y le faciliten una historia del recorrido realizado hasta el momento. Incluso, sería muy recomendable, que estas señales permitieran elaborar anotaciones de la misma manera que nosotros actualmente anotamos en las hojas de los libros observaciones o comentarios. Poco ganamos si sabemos la historia de nuestro recorrido por el documento pero no podemos recoger en él o en los señaladores aquellos puntos o partes que nos han resultado especialmente interesantes o por el contrario aquellas que no nos han aportado ningún conocimiento nuevo o pertinente a la información buscada.

En suma, mapas o sumarios, índices y herramientas de orientación hacen posible que:

- el lector conozca el contenido global del documento y su plan de organización,

- decida las vías y estrategias que va a seguir

- sepa la historia de su recorrido para volver a realizarlo y recrearlo cuantas veces desee.

\section{Nuevos usuarios, nuevas actitudes}

El hiperdocumento se caracteriza porque ofrece una nueva organización de la información, lo que implica un cambio de actitud por parte del usuario: El lector y el documento ya no son un sujeto y un objeto respectivamente, sino que ahora se reconocen mutuamente como dos "sujetos" capaces de de formularse preguntas y ofrecerse respuestas, capaces, en suma, de desarrollar actividades entre ellos, de ahí que hablemos de interactividad.

Se exige al usuario que, con su participación, recree el documento. Ya no estamos ante un documento único cuyo contenido se puede aprehender leyendolo de principio a fin. En el hiperdocumento cada usuario, con sus continuas decisiones, conforma, en cada acto de lectura, un nuevo documento. Por eso, existirán, al menos, tantos documentos diferentes como usuarios accedan a él . Y lo más importante es que esas lecturas diversas, realizadas por otros tantos usuarios-lectores, serán válidas en la medida en que el usuario pueda encontrar en ellas información, buscada o no, y haya logrado no perderse por los caminos que el emisor-productor le presenta.

Scire. 3 : 1 (ene. -jun. 1997) 87-97 
Por otra parte y aunque resulte contradictorio, se acentua la pasividad del usuario, en tanto que no se exige de él un desplazamiento físico para obtener la información. Cualquier usuario conectado desde su casa o su centro de trabajo a una red puede acceder a la información deseada sin por ello estar obligado a moverse del sitio en que se encuentra.

Esto da lugar a hábitos y actitudes informativas antes inusuales: El usuario puede consultar varios periódicos nacionales y algunos extranjeros, contrastar informaciones y crearse una opinión personal fuertemente fundamentada., incluso ir más allá y conseguir que se le suministre solamente aquella información que se ajuste a su perfil de preferencias o necesidades. Esto último, la información a la carta, representa una ventaja para el usuario pero también le supone una pérdida. La consecución de la información es una acción que se lleva cabo de forma individual y des-socializada. La segmentación y especificidad de la información resultante puede hacer que el usuario se cierre más y más en sí mismo y en su realidad circundante, olvidando la otra realidad, la de los otros que viven a su lado pero que no tienen sus mismas características. Puede ocasionar una cerrazón cultural y social importante, y convertirse en un peligro acechante.

\section{A modo de final}

Las innovaciones tecnológicas, como hemos visto, han modificado esencialemte la interacción entre los elementos implicados en el proceso informativo documental configurando una nueva perspectiva desde la que abordar el acto de la lectura. Loshiper-documentos exigen, así una meta/poli-lectura que se caracteriza porque:

- necesita de la mediación de un aparato: el ordenador

- supera la organización lineal o secuencial del conocimiento, proponiendo una estructura de caracter asociativo

- exige por parte del usuario una actitud interactiva, y una contemplación del documento, no como objeto, sino como sujeto

- hace patente un decrecimiento del componente textual y un incremento del componente icónico-visual.

Nos queda por analizar, siquiera brevemente, el futuro del hiperdocumento. Está claro que estamos ante una nueva forma de acceder al conocimiento en plena ascensión. Desde la introducción en Internet del modelo World Wide Web todo ha pasado a convertirse en documento hipertexto/hipermedia. No obstante el hiperdocumento es un medio en desarrollo pero, eso sí, en desarrollo pujante. Nos encontramos en un periodo de transición en el que coexisten el documento analógico y el digital. El trasporte de bits, como afirma Negroponte (1995, p. 99 y ss.) resulta más barato y más rápido que el trasporte del elemento físico: libro,

Scire. 3 : 1 (ene. -jun. 1997) 87-97 
disco, video; así que tarde o temprano estos soportes terminarán sucumbiendo ante la forma digital, de la misma manera que los discos compactos de música han desplazado a los discos de vinilo. Todo es cuestión de tiempo, de aclimatación por parte de los usuarios y de que las tecnologías que los hacen posibles rebajen considerablemente sus precios.

Hoy por hoy, en España todavía son pocos los usuarios que pueden acceder a la técnología digital, el ordenador aún no es un electrodoméstico más de la casa, las conexiones a la red desde domicilios particulares son escasas, a pesar de que los precios por llamada/hora hayan bajado considerablemente en los últimos tiempos. Los usuarios que acceden a estos documentos pertenecen a élites, casi en su mayoría, profesionales o científicas. En suma, no podemos decir que sea un medio asequible ni facilmente accesible, todo ello sin nombrar la incomodidad del aparato lector; o el hecho de que el acceso a la información deba hacerse desde un punto fijo de la casa o del trabajo.

No obstante, es una realidad que tenemos ante nosotros, que nos invade y sobre la que vale la pena reflexionar.

\section{Referencias}

Barrueco Cruz, J. M. ; Garcia Testal, C. ; Gimeno, Mª J. (1996). Una aproximación a las revistas científicas en formato electrónico. // Revista Española de Documentación Científica. $19: 3$ (1996) 304-313.

Bazin, P. (1996). Vers une métalecture // Bulletin des Bibliothèques de France. Paris. 41 : 1 (1996) 8-14.

Canals Cabiro, I. (1990). El concepto de hipertexto y el futuro de la documentación // III ${ }^{\mathrm{a}}$ Jornadas Españolas de Documentación Automatizada : DOCUMAT 90. Palma de Mallorca : Universitat de les Illes Balears, 1990, p. 49-73.

Canals Cabiro, I. (1990). Introducción al hipertexto como herramienta general de información. Concepto, sistemas y problemática. // Revista Española de Documentación Científica. $13: 2$ (1990) 685-709.

Caridad, M.; Moscoso, P. (1991). Los sistemas de hipertexto e hipermedios. Salamanca; Madrid : Fundación Germán Sánchez Ruipérez; Pirámide, 1991.

Castells, M. (1995). La sociedad de la información: diez tesis. Temas para el debate. 5 (1995) 64-68.

Codina, L. (1996). El Llibre digital: una exploración sobre la informació electrònica i el futur de l'edició. Barcelona : Generalitat, 1996.

Diaz, P., Catenazzi, N.; Aedo, I. (1994). De la multimedia a la Hipermedia. Madrid : Rama, 1996.

Escolar, H. (1984). Historia del libro. Salamanca ; Madrid : Fundación Germán Sánchez Ruipérez ; Pirámide, 1984.

Garcia Marco, F. J. (1994). Hypertexto y Lenguajes Documentales : retos y sinergias. // IV Jornadas españolas de documentación automatizada : DOCUMAT'94.

Scire. 3 : 1 (ene. -jun. 1997) 87-97 
Universidad de Oviedo : 1994. 417-426.

Garcia Marco, F. J. (1996). Vannebar Bush, el hipertexto y el futuro del documento. // Tramullas, J. (Ed.). Tendencias de investigación en Documentación. Zaragoza : Universidad de Zaragoza, 1996. p. 185-210.

Landow, G. P. (1995). Hipertexto: la convergencia de la teoría crítica contemporánea y la tecnología. Madrid : Paidós, 1995.

Moscoso, P. (1990). Sistemas de hipermedios : desarrollo y configuración. // Revista Española de Documentación Científica. 13 : 3-4 (1990) 823-841.

Negroponte, N.(1995). El mundo digital. Barcelona : Ediciones B, 1995.

Río Sadornil, J. L. del (1992). Los hipertexto, hipermedia, hiperdocumento: una revolución creativa en la informática documental. // Documentación de las Ciencias de la Información. Madrid : Editorial Complutense, 1992. p. 83-99.

Scire. $3: 1$ (ene. -jun. 1997) 87-97 